\title{
Analytical Performance of Sensitivity and Specificity for Rapid Multiplex High Risk Human Papillomavirus Detection Kit: HPV ViroCheck
}

Sunyoung Park ${ }^{1, \dagger}$, Hyeonseok Yoon ${ }^{2, \dagger}$, Hyeeun Bang ${ }^{1}$, Yeun Kim ${ }^{1}$, Seongkyung Choi ${ }^{2}$, Sungwoo Ahn ${ }^{1}$, Jungho Kim ${ }^{1}$, Suji Lee ${ }^{1}$, Ji Yeong Yang ${ }^{1}$, Dongsup Lee ${ }^{3}$

${ }^{1}$ Department of Biomedical Laboratory Science, College of Health Sciences, Yonsei University, Wonju, Korea

${ }^{2}$ Optipharm M\&D, Inc., Wonju Eco Environmental Technology Center, Wonju, Korea

${ }^{3}$ Department of Clinical Laboratory Science, Hyejeon College, Hongseoung, Korea

\section{고위험군 HPV 검출을 위한 분석적 민감도와 특이도 성능평가}

\author{
박선영 $^{1, \dagger}$, 윤현석 $^{2, \dagger}$, 방혜은 $^{1}$, 김 연 $^{1}$, 최성경 ${ }^{2}$, 안성우 $^{1}$, 김정호 $^{1}$, 이수지 $^{1}$, 양지영 $^{1}$, 이동섭 $^{3}$ \\ ${ }^{1}$ 연세대학교 임상병리학과, ${ }^{2}$ 옵티팜 엠엔디, ${ }^{3}$ 혜전대학교 임상병리과
}

\begin{abstract}
Human papillomaviruses (HPVs) are major causes of cervical cancer. Sixteen high risk HPVs, including HPV 16, HPV 18, HPV31, HPV 33, HPV 35, HPV 39, HPV 45, HPV 51, HPV 52, HPV 53, HPV 56, HPV 58, HPV 59, HPV 66, HPV 68, and HPV 69 are found in cervical cancer. HPVs 16 and 18 are mainly presented in $70 \%$ of cervical cancer. Therefore, identifying the presence of these high-risk HPVs is crucial. The objective of this study is to establish the HPV ViroCheck for detecting 16 HR-HPVs and genotypes of HPVs 16 and 18, as well as to analyze the analytical performance of HPV ViroCheck. We performed the analytical sensitivity of HPV E6 / E7 genes of 16 high risk HPVs to confirm the limit of detection. Then, a cross reactivity of HPV ViroCheck with microorganisms and viruses related to the cervix were analyzed for analytical specificity. Analytical sensitivity of high risk HPV genotypes ranged from 1 to 100 copies when using cloned DNAs. The limit of detection was 10 cells for both SiHa and HeLa cells. Cervical-related microorganisms and viruses did not show cross-reactivity to HPV DNA. Moreover, the intra- and inter-assay coefficient variations (CVs) were below $5 \%$. In conclusion, HPV Virocheck will be useful for the detection of $16 \mathrm{HR}$ HPVs, as well as HPV 16 and HPV 18 genotypes rapidly.
\end{abstract}

Key words: Cervical cancer, Human papillomavirus, E6/E7, Sensitivity, Specificity

This is an Open Access article distributed under the terms of the Creative Commons Attribution Non-Commercial License (http://creativecommons.org/licenses/by-nc/4.0) which permits unrestricted non-commercial use, distribution, and reproduction in any medium, provided the original work is properly cited.

Copyright ( 2017 The Korean Society for Clinical Laboratory Science. All rights reserved.
${ }^{\dagger}$ The first two authors contributed equally to this work.

Corresponding author: Dongsup Lee Department of Clinical Laboratory Science, Hyejeon College, Daehakgil 25, Hongseoung-eup, Hongseoung-gun, Chungcheongnam-do 32244, Korea Tel: 82-41-630-5342 Fax: 82-33-760-2561 E-mail: eastern3547@naver.com

Received: October 12, 2017 Revised $1^{\text {st: }}$ October 24, 2017 Revised $2^{\text {nd }}:$ November 1, 2017 Accepted: November 1, 2017

\section{INTRODUCTION}

High risk (HR) human papillomavirus (HPV) is major cause of cervical cancer [1]. Epidemiologic evidence in cervical cancer was shown 16 HR HPVs, following (HPV $16,18,31,33,35,39,45,51,52,53,56,58,59,66,68$, and
69) among 100 known HPV types [2]. Especially, HPV16 and 18 are account for approximately $70 \%$ of all cervical cancers [2,3]. The presence of HR-HPV is complementarily used as a cervical cancer screening with cervical cytology test for preventing invasive cervical cancer [4].

HPV DNA tests, as developed for early cancer screening 
using molecular biology techniques, were recommended by the clinical guidelines implemented from American society for colposcopy and cervical pathology. The combination of an HPV DNA test and a Pap test in cervical cancer screening have been focused since 2009 [4,5]. Now, HPV and Pap co-testing were required for routine screening in initial assessment and the management guidelines for over 20s years old women [6].

In the Korean Society of Gynecologic Oncology, importance of HPV tests was stand out. It was recommended that specific HPV types in HR HPV-positive/cytology-negative women, and a positive test for HPV 16 or 18 should lead to colposcopy [7]. Especially, women for HPV 16 and/or 18 with ASC-US or LSIL cytology can be diagnosed directly to colposcopy and shown positive results $[7,8]$.

As HPV infection on diagnosis of cervical cancer is increasingly important, the oncogenic process in cervical cancer is studied and the upregulation of HPV E6/E7 oncoproteins is a marker for an increased risk of cervical cancer [9.10]. HPV E6 oncoproteins promote degradation of p53 and disrupts the function of the apoptosis $[11,12]$. HPV E7 oncoproteins inactivates pRb and dysregulates cell cycle [13,14]. Therefore, detection of E6/E7 oncogene expression could be more specific and a better predictor of cervical cancer risk than the detection of HPV DNA.

In our previous study, HPV E6/E7 oncogenic detection showed better specificity than HPV commercialized DNA kit [15]. Now, we developed E6/E7 based tests and commercialized. In this study, we evaluated the newly developed HPV E6/E7 tests, which detects 16 HR HPVs as well as major types of HPV 16 and HPV 18. HPV plasmid DNA and HPV infected cells were examined by analytical sensitivity, specificity, and reproducibility test.

\section{MATERIALS AND METHODS}

\section{Control plasmid DNA}

Plasmid HPV DNA was prepared for usage as a positive control to determine the analytical sensitivity and specificity of the HPV genotyping kit. The plasmid DNA was prepared by inserting the synthesized E6 and E7 regions of each HPV genotype into pCR2.1 vectors (Invitrogen, Carlsbad, USA), and the concentration was adjusted to $2 \times 10^{8}$ copies with TE buffer (10 mM Tris-HCl, 1 mM EDTA, pH 8.0) and mixed with C33A (HPV negative) genomic DNA. The E6 and E7 regions of the 16 high-risk HPV types were confirmed on the basis of Genbank blast. All plasmid HPV DNA constructs were confirmed by PCR-amplified DNA sequencing.

\section{Cell lines}

SiHa, HeLa, and C33A cells were purchased from American Type Culture Collection (ATTC, Manassas, USA) and Korean Cell Line Bank (Seoul, Korea). SiHa cells and HeLa were cultured in Dulbecco's MEM (DMEM) Eagle, with 10\% fetal bovine serum (FBS), and standard antibiotics. C33A cells were cultured in Minimal Essential Medium(MEM) Eagle with 10\% FBS, and standard antibiotics. Cells were counted using a T20 ${ }^{\mathrm{TM}}$ Automated cell counter (Bio-Rad, Hercules, USA) according to manufacturer's instructions. Each cell was measured by $10^{6}$ cells $/ \mathrm{mL}$.

\section{DNA extraction}

DNA was extracted from $1.0 \mathrm{~mL}$ of each counted cell line using the $5 \%$ chelax-100 resin solution with boiling 5 min [15-17]. Template DNA was stored at $-20^{\circ} \mathrm{C}$ until use.

\section{Multiplex HPV E6/E7 real time PCR assay}

Detection of HPV E6/E7 in extracted DNA was performed by real time PCR. HPV ViroCheck assay kit (Optipharm M\&D, Osong, Korea) was performed using CFX-96 (Bio-Rad, Hercules, USA) real-time PCR systems for thermocycling and fluorescence detection, according to the manufacturers' instructions. The PCR primers and the corresponding TaqMan ${ }^{\circledR}$ probes were designed for three different sets of HPVs, in each case targeting their common sequence (Group I: HPV genotypes 16, 31, 33, 35, 52, and 58; Group II: HPV genotypes 18, 39, 45, 51, and 68; and Group III: HPV genotypes 53, 56, 59, 66, and 69). Real-time PCR amplification for HPV E6/E7 gene was performed in a total volume of $20 \mu \mathrm{L}$ containing $10 \mu \mathrm{L} 2 \times$ Thunderbird probe qPCR mix (Toyobo, Osaka, Japan), $5 \mu \mathrm{L}$ primer and TaqMan probe mixture, $2 \mu \mathrm{L}$ template $\mathrm{cDNA}$, and $3 \mu \mathrm{LDW}$ 
for each well.

The multiplex RT-qPCR assay detected HPV E6/E7 genes, simultaneously in three tubes by incorporating alpha 9, alpha 7, and alpha 5,6-specific TaqMan probes (HEX), HPV 16 and HPV 18 specific probes (FAM), and internal controls (CY5) labeled with different fluorophores. Positive controls were included throughout the procedure. No-template controls with sterile DW instead of template DNA were incorporated into each run. Cycling conditions were $95^{\circ} \mathrm{C}$ for $3 \mathrm{~min}$, followed by 40 cycles of $95^{\circ} \mathrm{C}$ for $3 \mathrm{~s}$ and $55^{\circ} \mathrm{C}$ for $30 \mathrm{~s}$. The detection of HPV was determined by the cycle threshold (Cq), which is the number of PCR cycles required for the fluorescence to exceed a value significantly higher than the background fluorescence. To avoid false negatives of HPV infection in samples, glycer- aldehyde-3-phosphate dehydrogenase (GAPDH) was used as a control.

\section{Statistical analysis}

All statistical analyses were performed using Prism 5 software (GraphPad, La Jolla, CA, USA) and SPSS statistics software version 21.0 (IBM, Armonk, NY, USA). Cq average, 95\% confidence interval (CI), and coefficient of variation (CV) for HPV ViroCheck analytical sensitivity of cloned DNA and cell lines.
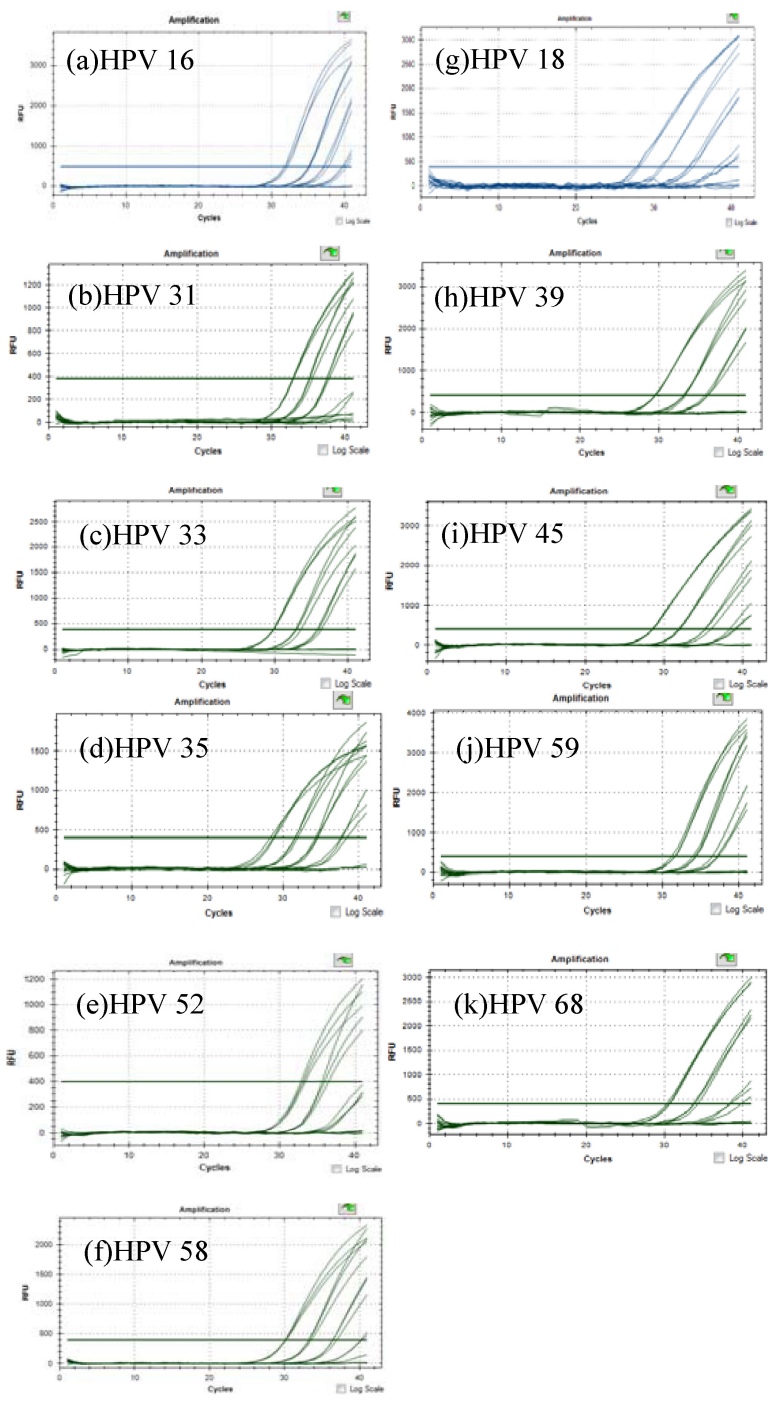
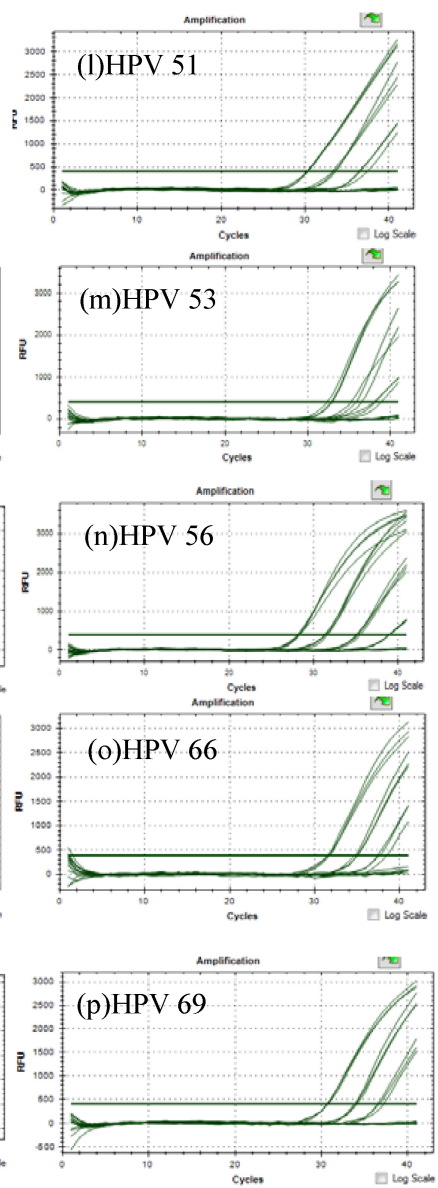

Figure 1. Representative 16 high risk HPVs graph from real time PCR data. Group I: HPV genotypes 16, 31, 33, 35, 52, and 58 (a f); Group II: HPV genotypes 18, 39, 45, 59, and 68 (g k); and Group III: HPV genotypes 51, 53, 56, 59, 66, and $69(\mathrm{j} \sim \mathrm{p})$. Real The representative 16 HR HPV types with 1000 copies, 100 copies, 10 copies, and 1 copy were measured in replicates of 10 times, resulting in a total of 20 replicates, over 3 days by RT-qPCR. 


\section{RESULTS}

\section{Analytical sensitivity in HPV copies of plasmid HPV DNA}

The limit of detection (LoD), which indicate 95\% detection rates, were determined according to the methods in the KFDA HPV guideline document. The cloned 16 HR HPV types plasmid DNAs with 1000 copies, 100 copies, 10 copies, and 1 copy were measured in replicates of 10 times, resulting in a total of 20 replicates, over 3 days by RT-qPCR. The representative 16 HR HPV types with 1000 copies, 100 copies, 10 copies, and 1 copy from real time PCR were shown in Figure 1. The 1 copy of LoD in HPV 16 and HPV 31 was shown. 10 copies of LoD were HPV 33,
HPV 52, HPV 35, HPV 53, HPV 59, HPV 66, and HPV 69. 100 copies of LoD were HPV 18, HPV 39, HPV 45, HPV 51, HPV 56, HPV 58, and HPV 68. All of cloned 16 HPV types plasmid DNAs were detected below 100 copies/test and CV was below 3\% (Table 1).

\section{Analytical sensitivity in HPV infected cell lines}

To find out how many cells from cervical cancer can be detected, the LoD of cervical cancer cell lines, which were HPV 16 infected SiHa, HPV 18 infected HeLa, and HPV negative C33A, was performed in replicates of 10 times, resulting in a total of 20 replicates, over 3 days by RT-qPCR. The mean of GAPDH in 20 replicates was 38.7 (95\% CI 38.6 38.8) and 39.1 (95\% CI 39.1 39.2) in $\mathrm{SiHa}$

Table 1. Limit of detection for 16 high risk HPVs through 20 repeated tests

\begin{tabular}{|c|c|c|c|c|c|}
\hline & & \multicolumn{4}{|c|}{ Copy number of plasmids per test } \\
\hline & & 1000 copies & 100 copies & 10 copies & 1 copy \\
\hline \multirow[t]{2}{*}{ HPV 16} & Cq avg $(95 \% \mathrm{Cl})$ & $31.7(31.6 \sim 31.8)$ & $35.1(35.0 \sim 35.2)$ & $37.8(37.6 \sim 38.1)$ & $39.2(39.0 \sim 39.5)$ \\
\hline & CV & $0.6 \%$ & $0.7 \%$ & $1.6 \%$ & $1.5 \%$ \\
\hline \multirow{2}{*}{ HPV 31} & $\mathrm{Cq}$ avg $(95 \% \mathrm{Cl})$ & $32.5(32.3 \sim 32.6)$ & $35.0(34.9 \sim 35.1)$ & $37.1(36.8 \sim 37.3)$ & $39.2(38.9 \sim 39.4)$ \\
\hline & CV & $1.1 \%$ & $0.9 \%$ & $1.4 \%$ & $1.5 \%$ \\
\hline \multirow[t]{2}{*}{ HPV 33} & Cq avg $(95 \% \mathrm{Cl})$ & $33.0(32.9 \sim 33.1)$ & $36.1(35.8 \sim 36.4)$ & $39.1(38.8 \sim 39.3)$ & N/A \\
\hline & CV & $0.6 \%$ & $2.0 \%$ & $1.5 \%$ & - \\
\hline \multirow[t]{2}{*}{ HPV 52} & Cq avg $(95 \% \mathrm{Cl})$ & $32.9(32.8 \sim 33.0)$ & $36.2(35.9 \sim 36.4)$ & $39.0(38.8 \sim 39.3)$ & N/A \\
\hline & CV & $0.9 \%$ & $1.3 \%$ & $1.3 \%$ & - \\
\hline \multirow[t]{2}{*}{ HPV 58} & Cq avg $(95 \% \mathrm{Cl})$ & $33.5(33.4 \sim 33.6)$ & $36.8(36.7 \sim 37.0)$ & $N / A$ & N/A \\
\hline & $\mathrm{CV}$ & $0.8 \%$ & $1.0 \%$ & - & - \\
\hline \multirow[t]{2}{*}{ HPV 39} & $\mathrm{Cq}$ avg $(95 \% \mathrm{Cl})$ & $32.8(32.5 \sim 33.2)$ & $36.6(36.3 \sim 36.8)$ & $\mathrm{N} / \mathrm{A}$ & $N / A$ \\
\hline & CV & $2.5 \%$ & $1.5 \%$ & - & - \\
\hline \multirow[t]{2}{*}{ HPV 53} & $\mathrm{Cq}$ avg $(95 \% \mathrm{Cl})$ & $32.7(32.6 \sim 32.8)$ & $36.0(35.8 \sim 36.3)$ & $37.7(36.8 \sim 38.6)$ & N/A \\
\hline & CV & $0.9 \%$ & $1.7 \%$ & $5.7 \%$ & N/A \\
\hline \multirow[t]{2}{*}{ HPV 18} & Cq avg $(95 \% \mathrm{Cl})$ & $31.4(30.9 \sim 32.0)$ & $34.8(34.5 \sim 35.1)$ & $\mathrm{N} / \mathrm{A}$ & N/A \\
\hline & CV & $4.3 \%$ & $2.2 \%$ & - & - \\
\hline \multirow[t]{2}{*}{ HPV 56} & $\mathrm{Cq}$ avg $(95 \% \mathrm{Cl})$ & $31.5(31.4 \sim 31.6)$ & $35.0(34.8 \sim 35.3)$ & N/A & N/A \\
\hline & CV & $0.7 \%$ & $1.4 \%$ & - & - \\
\hline \multirow[t]{2}{*}{ HPV 35} & $\mathrm{Cq}$ avg $(95 \% \mathrm{Cl})$ & $30.3(30.2 \sim 30.4)$ & $33.4(33.3 \sim 33.5)$ & $36.6(36.3 \sim 36.9)$ & $\mathrm{N} / \mathrm{A}$ \\
\hline & CV & $1.0 \%$ & $0.8 \%$ & $1.9 \%$ & - \\
\hline \multirow[t]{2}{*}{ HPV 45} & $\mathrm{Cq}$ avg $(95 \% \mathrm{Cl})$ & $31.8(31.7 \sim 31.9)$ & $35.5(35.3 \sim 35.6)$ & N/A & N/A \\
\hline & CV & $1.0 \%$ & $1.1 \%$ & - & - \\
\hline \multirow[t]{2}{*}{ HPV 51} & Cq avg $(95 \% \mathrm{Cl})$ & $33.4(33.2 \sim 33.5)$ & $36.9(36.7 \sim 37.2)$ & $N / A$ & N/A \\
\hline & CV & $1.1 \%$ & $1.7 \%$ & - & - \\
\hline \multirow[t]{2}{*}{ HPV 59} & $\mathrm{Cq}$ avg $(95 \% \mathrm{Cl})$ & $31.4(31.3 \sim 31.5)$ & $34.7(34.5 \sim 35.0)$ & $37.9(37.6 \sim 38.2)$ & $\mathrm{N} / \mathrm{A}$ \\
\hline & $\mathrm{CV}$ & $0.8 \%$ & $1.5 \%$ & $2.0 \%$ & - \\
\hline \multirow[t]{2}{*}{ HPV 66} & Cq avg $(95 \% \mathrm{Cl})$ & $31.5(31.4 \sim 31.6)$ & $34.7(34.5 \sim 35.0)$ & $38.1(37.7 \sim 38.5)$ & N/A \\
\hline & $\mathrm{CV}$ & $0.8 \%$ & $1.6 \%$ & $2.3 \%$ & - \\
\hline \multirow[t]{2}{*}{ HPV 68} & Cq avg $(95 \% \mathrm{Cl})$ & $34.7(34.5 \sim 35.0)$ & $38.6(38.3 \sim 38.9)$ & N/A & N/A \\
\hline & CV & $1.6 \%$ & $1.8 \%$ & - & - \\
\hline \multirow[t]{2}{*}{ HPV 69} & $\mathrm{Cq}$ avg $(95 \% \mathrm{Cl})$ & $33.7(33.5 \sim 33.9)$ & $37.3(36.9 \sim 37.6)$ & $39.4(39.3 \sim 39.6)$ & N/A \\
\hline & CV & $1.5 \%$ & $2.3 \%$ & $0.8 \%$ & - \\
\hline
\end{tabular}

Abbreviations: Cq avg, average of quantification cycles in 20 repeated tests; 95\% Cl, 95\% confidence interval; N/A, not amplified. 
and HeLa cells and detected by 10 cells each. The mean of Group I in SiHa cell was 39.1 (95\% CI 39.0 39.2) and the mean of Group II in HeLa cell was 38.9 (95\% CI 38.9 39.0). Both were detected by 10 cells (Table 2).

\section{Cross-reactivity for 16 HR HPV types}

In order to confirm whether bacteria and virus, which are normal flora or sexually transmitted infectious agents in female genitalia show cross-reactivity, analytical specificity were performed with 23 bacteria and 23 virus including $16 \mathrm{HR} \mathrm{HPV}$ types. The $10^{5} \mathrm{PFU} / \mathrm{mL}$ for virus and $10^{6} \mathrm{CFU} / \mathrm{mL}$ for bacteria at medically significant concentrations with HPV negative C33A cell lines were used. C33A with bacteria or virus and without bacteria or virus alternately were repeated 3 times at one reaction and performed over 5 times, resulting in a total of 15 times. No cross reactions were confirmed for Groups I, II and III (Table 3).

\section{Precision of plasmid HR HPV DNA}

For precision test, a total number of measurements per sample was 144 (12 days $\times 2$ runs/day $\times 2$ replicates $\times 3$ lots). HPV 16 clone DNA for FAM dye of Group I, HPV 33 clone DNA for HEX dye of Group I, HPV 18 clone DNA for FAM of Group II, HPV 39 clone DNA for HEX of Group II, HPV 53 clone DNA for HEX with 500 copies, 100 copies, and negative were used. The total within-run CV ranged from $0 \%$ to $0.2 \%$ for HPV $16,0.2 \%$ to $0.3 \%$ for HPV $33,0.1 \%$ to $0.4 \%$ for HPV $18,0.1 \%$ to $0.3 \%$ for HPV $39,0.4 \%$ to $0.5 \%$ for HPV 53, and 0.2 to 0.3 for HPV 56. The total between-run CV ranged from 0\% to 0.2\% for HPV 16, 0\% for HPV $33,0.3 \%$ to $0.4 \%$ for HPV $18,0.1 \%$ to $0.2 \%$ for HPV $39,0.3 \%$ to $0.4 \%$ for HPV 53, and 0.1 to 0.2 for HPV 56 . The total between-day CV ranged from $1.3 \%$ to $2.8 \%$ for HPV $16,1.9 \%$ to $2.1 \%$ for HPV $33,2.0 \%$ to $2.5 \%$ for HPV $18,2.1 \%$ for HPV 39, $1.9 \%$ to $2.9 \%$ for HPV 53, and $2.5 \%$ to $3.2 \%$ for HPV 56. The total lot to lot CV ranged from $0.0 \%$ to $0.2 \%$ for HPV $16,0.4 \%$ to $0.6 \%$ for HPV $33,0.3 \%$ for HPV $18,0.5 \%$ to $1.0 \%$ for HPV $39,0.1 \%$ to $0.4 \%$ for HPV 53 , and $0.5 \%$ to $0.6 \%$ for HPV 56 (Table 4).

\section{DISCUSSION}

HPV ViroCheck kit detecting HPV 16 and HPV18 genotyping as well as 16 HR HPVs demonstrated a high degree of analytical sensitivity, analytical specificity, within laboratory precision. To assess the performance of the HPV ViroCheck assay, the cloning and sequencing of plasmid HPV DNA, which is confirmed to obtain the reliable results, was used as a reference standard. Also, HeLa and SiHa cell lines were confirmed, respectively. HeLa cell lines contain 10 50 copies of HPV 18 DNA/cell and SiHa cell lines contain 1 2 copies and HPV 16 DNA/cell from Mincheva et al study [18]. Considering the reference, HPV 18 was detected by 100 copies/test and HPV 16 was detected by 1 copy/test. Each minimum detection sensitivity of HR HPVs ranged from 1 copy/test to 1000 copies/test in both plasmid HR HPV DNA and HPV infection cells was same (Table 1 and Table 2) and shown the DNA concentration dependent HPV detection (Figure

Table 2. Limit of detection in cervical cancer cells

\begin{tabular}{|c|c|c|c|c|c|c|}
\hline & & \multicolumn{5}{|c|}{ Cells per test } \\
\hline & & 10000 & 1000 & 100 & 10 & 1 \\
\hline $\begin{array}{l}\mathrm{SiHa} \\
(\mathrm{HPV} 16) \\
(\mathrm{N}=20)\end{array}$ & $\begin{array}{l}\text { GAPDH Cq } \\
\text { CV } \\
\text { Group I Cq } \\
\text { CV }\end{array}$ & $\begin{array}{c}28.3(28.3 \sim 28.4) \\
0.5 \% \\
29.8(29.7 \sim 29.9) \\
0.7 \%\end{array}$ & $\begin{array}{c}31.6(31.5 \sim 31.7) \\
0.8 \% \\
33.1(33.0 \sim 33.3) \\
1.0 \%\end{array}$ & $\begin{array}{c}35.1(34.9 \sim 35.2) \\
1.0 \% \\
36.8(36.5 \sim 37.1) \\
1.9 \%\end{array}$ & $\begin{array}{c}38.0(37.7 \sim 38.4) \\
2.1 \% \\
39.1(39.0 \sim 39.2) \\
0.6 \%\end{array}$ & $\begin{array}{c}38.7(38.6 \sim 38.8) \\
0.8 \% \\
N / A \\
-\end{array}$ \\
\hline $\begin{array}{l}\text { HeLa } \\
(\mathrm{HPV} 18) \\
(\mathrm{N}=20)\end{array}$ & $\begin{array}{l}\text { GAPDH Cq } \\
\text { CV } \\
\text { Group } \| \mathrm{Cq} \\
\text { CV }\end{array}$ & $\begin{array}{c}29.1(29.0 \sim 29.2) \\
0.5 \% \\
29.2(29.1 \sim 29.3) \\
0.8 \%\end{array}$ & $\begin{array}{c}32.5(32.2 \sim 32.8) \\
2.3 \% \\
32.6(32.5 \sim 32.7) \\
0.7 \%\end{array}$ & $\begin{array}{c}36.0(35.9 \sim 36.2) \\
1.3 \% \\
36.4(36.1 \sim 36.8) \\
2.4 \%\end{array}$ & $\begin{array}{c}38.0(37.7 \sim 38.2) \\
1.7 \% \\
38.9(38.9 \sim 39.0) \\
0.4 \%\end{array}$ & $\begin{array}{c}39.1(39.1 \sim 39.2) \\
0.6 \% \\
\text { N/A } \\
-\end{array}$ \\
\hline
\end{tabular}

Abbreviations: Cq, quantification cycles; N/A, not amplified. 
Table 3. Specificity of multiplex HR HPVs using cervix related pathogens

\begin{tabular}{|c|c|c|c|c|c|c|c|c|c|}
\hline \multirow{2}{*}{ Bacteria } & \multirow{2}{*}{$\begin{array}{l}\mathrm{CFU} / \\
\mathrm{mL}\end{array}$} & \multicolumn{3}{|c|}{$\begin{array}{l}\text { Analytical specificity } \\
\text { (Positive } \mathrm{n} / \text { total) }\end{array}$} & \multirow[t]{2}{*}{ Viruses } & \multirow{2}{*}{$\begin{array}{c}\text { Copies/ } \\
\mathrm{mL}\end{array}$} & \multicolumn{3}{|c|}{$\begin{array}{l}\text { Analytical specificity } \\
\text { (Positive } \mathrm{n} / \text { total) }\end{array}$} \\
\hline & & Group I & Group II & Group III & & & Group I & Group II & Group III \\
\hline $\begin{array}{l}\text { Lactobacillus } \\
\text { acidophilus }\end{array}$ & $10^{6}$ & $\begin{array}{l}100 \% \\
(0 / 15)\end{array}$ & $\begin{array}{l}100 \% \\
(0 / 15)\end{array}$ & $\begin{array}{l}100 \% \\
(0 / 15)\end{array}$ & Adenovirus 2 & $10^{5}$ & $\begin{array}{l}100 \% \\
(0 / 15)\end{array}$ & $\begin{array}{l}100 \% \\
(0 / 15)\end{array}$ & $\begin{array}{l}100 \% \\
(0 / 15)\end{array}$ \\
\hline $\begin{array}{l}\text { Staphylococcus } \\
\text { epidermidis }\end{array}$ & $10^{6}$ & $\begin{array}{l}100 \% \\
(0 / 15)\end{array}$ & $\begin{array}{l}100 \% \\
(0 / 15)\end{array}$ & $\begin{array}{l}100 \% \\
(0 / 15)\end{array}$ & Adenovirus 5 & $10^{5}$ & $\begin{array}{l}100 \% \\
(0 / 15)\end{array}$ & $\begin{array}{l}100 \% \\
(0 / 15)\end{array}$ & $\begin{array}{l}100 \% \\
(0 / 15)\end{array}$ \\
\hline $\begin{array}{l}\text { Streptococcus } \\
\text { faecalis }\end{array}$ & $10^{6}$ & $\begin{array}{l}100 \% \\
(0 / 15)\end{array}$ & $\begin{array}{l}100 \% \\
(0 / 15)\end{array}$ & $\begin{array}{l}100 \% \\
(0 / 15)\end{array}$ & Cytomegalovirus & $10^{5}$ & $\begin{array}{l}100 \% \\
(0 / 15)\end{array}$ & $\begin{array}{l}100 \% \\
(0 / 15)\end{array}$ & $\begin{array}{l}100 \% \\
(0 / 15)\end{array}$ \\
\hline $\begin{array}{l}\text { Streptococcus } \\
\text { pyogenes }\end{array}$ & $10^{6}$ & $\begin{array}{l}100 \% \\
(0 / 15)\end{array}$ & $\begin{array}{l}100 \% \\
(0 / 15)\end{array}$ & $\begin{array}{l}100 \% \\
(0 / 15)\end{array}$ & $\begin{array}{l}\text { Herpes simplex } \\
\text { virus } 1\end{array}$ & $10^{5}$ & $\begin{array}{l}100 \% \\
(0 / 15)\end{array}$ & $\begin{array}{l}100 \% \\
(0 / 15)\end{array}$ & $\begin{array}{l}100 \% \\
(0 / 15)\end{array}$ \\
\hline $\begin{array}{l}\text { Streptococcus } \\
\text { agalactiae }\end{array}$ & $10^{6}$ & $\begin{array}{l}100 \% \\
(0 / 15)\end{array}$ & $\begin{array}{l}100 \% \\
(0 / 15)\end{array}$ & $\begin{array}{l}100 \% \\
(0 / 15)\end{array}$ & $\begin{array}{l}\text { Herpes simplex } \\
\text { virus } 2\end{array}$ & $10^{5}$ & $\begin{array}{l}100 \% \\
(0 / 15)\end{array}$ & $\begin{array}{l}100 \% \\
(0 / 15)\end{array}$ & $\begin{array}{l}100 \% \\
(0 / 15)\end{array}$ \\
\hline $\begin{array}{l}\text { Corynebacterium } \\
\text { diphtheriae }\end{array}$ & $10^{6}$ & $\begin{array}{l}100 \% \\
(0 / 15)\end{array}$ & $\begin{array}{l}100 \% \\
(0 / 15)\end{array}$ & $\begin{array}{l}100 \% \\
(0 / 15)\end{array}$ & HPV 6 & $10^{5}$ & $\begin{array}{l}100 \% \\
(0 / 15)\end{array}$ & $\begin{array}{l}100 \% \\
(0 / 15)\end{array}$ & $\begin{array}{l}100 \% \\
(0 / 15)\end{array}$ \\
\hline $\begin{array}{l}\text { Peptostreptococcus } \\
\text { anaerobius }\end{array}$ & $10^{6}$ & $\begin{array}{l}100 \% \\
(0 / 15)\end{array}$ & $\begin{array}{l}100 \% \\
(0 / 15)\end{array}$ & $\begin{array}{l}100 \% \\
(0 / 15)\end{array}$ & HPV 11 & $10^{5}$ & $\begin{array}{l}100 \% \\
(0 / 15)\end{array}$ & $\begin{array}{l}100 \% \\
(0 / 15)\end{array}$ & $\begin{array}{l}100 \% \\
(0 / 15)\end{array}$ \\
\hline Klebsiella oxytoca & $10^{6}$ & $\begin{array}{l}100 \% \\
(0 / 15)\end{array}$ & $\begin{array}{l}100 \% \\
(0 / 15)\end{array}$ & $\begin{array}{l}100 \% \\
(0 / 15)\end{array}$ & HPV 16 & $10^{5}$ & - & $\begin{array}{l}100 \% \\
(0 / 15)\end{array}$ & $\begin{array}{l}100 \% \\
(0 / 15)\end{array}$ \\
\hline $\begin{array}{l}\text { Enterobacter } \\
\text { faecalis }\end{array}$ & $10^{6}$ & $\begin{array}{l}100 \% \\
(0 / 15)\end{array}$ & $\begin{array}{l}100 \% \\
(0 / 15)\end{array}$ & $\begin{array}{l}100 \% \\
(0 / 15)\end{array}$ & HPV 31 & $10^{5}$ & - & $\begin{array}{l}100 \% \\
(0 / 15)\end{array}$ & $\begin{array}{l}100 \% \\
(0 / 15)\end{array}$ \\
\hline Proteus vulgarus & $10^{6}$ & $\begin{array}{l}100 \% \\
(0 / 15)\end{array}$ & $\begin{array}{l}100 \% \\
(0 / 15)\end{array}$ & $\begin{array}{l}100 \% \\
(0 / 15)\end{array}$ & HPV 33 & $10^{5}$ & - & $\begin{array}{l}100 \% \\
(0 / 15)\end{array}$ & $\begin{array}{l}100 \% \\
(0 / 15)\end{array}$ \\
\hline $\begin{array}{l}\text { Bifidobacterium } \\
\text { breve }\end{array}$ & $10^{6}$ & $\begin{array}{l}100 \% \\
(0 / 15)\end{array}$ & $\begin{array}{l}100 \% \\
(0 / 15)\end{array}$ & $\begin{array}{l}100 \% \\
(0 / 15)\end{array}$ & HPV 35 & $10^{5}$ & - & $\begin{array}{l}100 \% \\
(0 / 15)\end{array}$ & $\begin{array}{l}100 \% \\
(0 / 15)\end{array}$ \\
\hline $\begin{array}{l}\text { Fusobacterium } \\
\text { mortiferum }\end{array}$ & $10^{6}$ & $\begin{array}{l}100 \% \\
(0 / 15)\end{array}$ & $\begin{array}{l}100 \% \\
(0 / 15)\end{array}$ & $\begin{array}{l}100 \% \\
(0 / 15)\end{array}$ & HPV 52 & $10^{5}$ & - & $\begin{array}{l}100 \% \\
(0 / 15)\end{array}$ & $\begin{array}{l}100 \% \\
(0 / 15)\end{array}$ \\
\hline $\begin{array}{l}\text { Neisseria } \\
\text { gonorrhoeae }\end{array}$ & $10^{6}$ & $\begin{array}{l}100 \% \\
(0 / 15)\end{array}$ & $\begin{array}{l}100 \% \\
(0 / 15)\end{array}$ & $\begin{array}{l}100 \% \\
(0 / 15)\end{array}$ & HPV 58 & $10^{5}$ & - & $\begin{array}{l}100 \% \\
(0 / 15)\end{array}$ & $\begin{array}{l}100 \% \\
(0 / 15)\end{array}$ \\
\hline $\begin{array}{l}\text { Mycoplasma } \\
\text { hominis }\end{array}$ & $10^{6}$ & $\begin{array}{l}100 \% \\
(0 / 15)\end{array}$ & $\begin{array}{l}100 \% \\
(0 / 15)\end{array}$ & $\begin{array}{l}100 \% \\
(0 / 15)\end{array}$ & HPV 18 & $10^{5}$ & $\begin{array}{l}100 \% \\
(0 / 15)\end{array}$ & - & $\begin{array}{l}100 \% \\
(0 / 15)\end{array}$ \\
\hline $\begin{array}{l}\text { Ureaplasma } \\
\text { urealyticum }\end{array}$ & $10^{6}$ & $\begin{array}{l}100 \% \\
(0 / 15)\end{array}$ & $\begin{array}{l}100 \% \\
(0 / 15)\end{array}$ & $\begin{array}{l}100 \% \\
(0 / 15)\end{array}$ & HPV 39 & $10^{5}$ & $\begin{array}{l}100 \% \\
(0 / 15)\end{array}$ & - & $\begin{array}{l}100 \% \\
(0 / 15)\end{array}$ \\
\hline $\begin{array}{l}\text { Bacteroids } \\
\text { fragilis }\end{array}$ & $10^{6}$ & $\begin{array}{l}100 \% \\
(0 / 15)\end{array}$ & $\begin{array}{l}100 \% \\
(0 / 15)\end{array}$ & $\begin{array}{l}100 \% \\
(0 / 15)\end{array}$ & HPV 45 & $10^{5}$ & $\begin{array}{l}100 \% \\
(0 / 15)\end{array}$ & - & $\begin{array}{l}100 \% \\
(0 / 15)\end{array}$ \\
\hline $\begin{array}{l}\text { Chlamydia } \\
\text { trachomatis }\end{array}$ & $10^{6}$ & $\begin{array}{l}100 \% \\
(0 / 15)\end{array}$ & $\begin{array}{l}100 \% \\
(0 / 15)\end{array}$ & $\begin{array}{l}100 \% \\
(0 / 15)\end{array}$ & HPV 59 & $10^{5}$ & $\begin{array}{l}100 \% \\
(0 / 15)\end{array}$ & - & $\begin{array}{l}100 \% \\
(0 / 15)\end{array}$ \\
\hline $\begin{array}{c}\text { Gardnerella } \\
\text { vaginalis }\end{array}$ & $10^{6}$ & $\begin{array}{l}100 \% \\
(0 / 15)\end{array}$ & $\begin{array}{l}100 \% \\
(0 / 15)\end{array}$ & $\begin{array}{l}100 \% \\
(0 / 15)\end{array}$ & HPV 68 & $10^{5}$ & $\begin{array}{l}100 \% \\
(0 / 15)\end{array}$ & - & $\begin{array}{l}100 \% \\
(0 / 15)\end{array}$ \\
\hline $\begin{array}{l}\text { Staphylococcus } \\
\text { aureus }\end{array}$ & $10^{6}$ & $\begin{array}{l}100 \% \\
(0 / 15)\end{array}$ & $\begin{array}{l}100 \% \\
(0 / 15)\end{array}$ & $\begin{array}{l}100 \% \\
(0 / 15)\end{array}$ & HPV 51 & $10^{5}$ & $\begin{array}{l}100 \% \\
(0 / 15)\end{array}$ & $\begin{array}{l}100 \% \\
(0 / 15)\end{array}$ & - \\
\hline Escherichia coli & $10^{6}$ & $\begin{array}{l}100 \% \\
(0 / 15)\end{array}$ & $\begin{array}{l}100 \% \\
(0 / 15)\end{array}$ & $\begin{array}{l}100 \% \\
(0 / 15)\end{array}$ & HPV 53 & $10^{5}$ & $\begin{array}{l}100 \% \\
(0 / 15)\end{array}$ & $\begin{array}{l}100 \% \\
(0 / 15)\end{array}$ & - \\
\hline $\begin{array}{c}\text { Enterococcus } \\
\text { cloaceae }\end{array}$ & $10^{6}$ & $\begin{array}{l}100 \% \\
(0 / 15)\end{array}$ & $\begin{array}{l}100 \% \\
(0 / 15)\end{array}$ & $\begin{array}{l}100 \% \\
(0 / 15)\end{array}$ & HPV 56 & $10^{5}$ & $\begin{array}{l}100 \% \\
(0 / 15)\end{array}$ & $\begin{array}{l}100 \% \\
(0 / 15)\end{array}$ & - \\
\hline $\begin{array}{c}\text { Pseudomonas } \\
\text { aeruginosa }\end{array}$ & $10^{6}$ & $\begin{array}{l}100 \% \\
(0 / 15)\end{array}$ & $\begin{array}{l}100 \% \\
(0 / 15)\end{array}$ & $\begin{array}{l}100 \% \\
(0 / 15)\end{array}$ & HPV 66 & $10^{5}$ & $\begin{array}{l}100 \% \\
(0 / 15)\end{array}$ & $\begin{array}{l}100 \% \\
(0 / 15)\end{array}$ & - \\
\hline $\begin{array}{l}\text { Candida } \\
\text { albicans }\end{array}$ & $10^{6}$ & $\begin{array}{l}100 \% \\
(0 / 15)\end{array}$ & $\begin{array}{l}100 \% \\
(0 / 15)\end{array}$ & $\begin{array}{l}100 \% \\
(0 / 15)\end{array}$ & HPV 69 & $10^{5}$ & $\begin{array}{l}100 \% \\
(0 / 15)\end{array}$ & $\begin{array}{l}100 \% \\
(0 / 15)\end{array}$ & - \\
\hline
\end{tabular}

Abbreviation: CFU, colongy forming units.

1). Therefore, the analytical detection limit of the assay was determined to provide enough fluorescence intensity to serve as the minimum detection sensitivity. Moreover, the analytical specificity was tested also using HPV negative cervical cancer cell line C33A along with 46 other types of microbial DNA including viruses and bacteria mixed with. There was no cross-reaction, demonstrating that the presence of other cervical related microbial DNA mixed with HPV DNA did not affect the performance of the assay (Table 3).

Currently, there are several commercially available HPV tests. Hybrid Capture2, which is approved by the FDA, is 
452 Sunyoung Park, et al. Multiplex High-Risk Human Papillomavirus Detection Kit

Table 4. Performance of inter-assay and intra-assay coefficients of variation

\begin{tabular}{|c|c|c|c|c|c|c|c|c|c|c|c|c|c|c|c|c|c|}
\hline & \multirow{2}{*}{ Copies } & \multirow{2}{*}{$\mathrm{N}-$} & \multicolumn{3}{|c|}{ Total } & \multicolumn{3}{|c|}{ Within-run } & \multicolumn{3}{|c|}{ Between-run } & \multicolumn{3}{|c|}{ Between-day } & \multicolumn{3}{|c|}{ Lot to lot } \\
\hline & & & Cq avg & SD & / (\%) & Cq avg & SD & CV (\%) & Cq avg & SD & CV (\%) & Cq avg & SD & CV (\%) & Cq avg & SD & CV $(\%)$ \\
\hline \multirow{3}{*}{$\begin{array}{l}\text { Group I } \\
\text { (HPV16) }\end{array}$} & 0 & 144 & N/A & - & 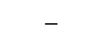 & 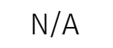 & - & - & 年 & - & 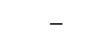 & 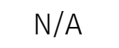 & 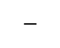 & 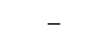 & T & 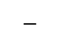 & 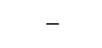 \\
\hline & 0 & 144 & 0.9 & 0.6 & $1.80 \%$ & 34 & 0 & $0.00 \%$ & 33.9 & 0.1 & $0.20 \%$ & 33.9 & 0.4 & $1.30 \%$ & 33.9 & 0 & $0.00 \%$ \\
\hline & 500 & 144 & 31.3 & 1 & $3.00 \%$ & 31.4 & 0.1 & $0.20 \%$ & 31.3 & 0 & $0.00 \%$ & 31.3 & 0.9 & $2.80 \%$ & 1.3 & 0 & $0.20 \%$ \\
\hline \multirow{3}{*}{$\begin{array}{l}\text { Group I } \\
\text { (HPV33) }\end{array}$} & 0 & 144 & 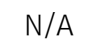 & - & - & $A$ & - & - & $\mathrm{N} / \mathrm{A}$ & - & - & $/ A$ & - & - & J/A & - & - \\
\hline & 100 & 144 & 4.9 & 0.7 & 10 & 34.9 & 0.1 & 0.30 & 34.9 & 0 & 0.00 & 34.9 & 0.7 & $1.90 \%$ & 34.9 & 0.1 & $40 \%$ \\
\hline & 500 & 144 & 2.3 & 0.8 & 24 & 32.3 & 0.1 & $0.20 \%$ & 32.4 & 0 & $0.00 \%$ & 32.4 & 0.7 & $2.10 \%$ & 32.4 & 0.2 & $0.60 \%$ \\
\hline \multirow{3}{*}{$\begin{array}{c}\text { Group II } \\
\text { (HPV18) }\end{array}$} & 0 & 144 & N/A & - & 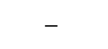 & $\mathrm{N} / \mathrm{A}$ & - & - & $\mathrm{N} / \mathrm{A}$ & - & 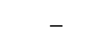 & $\mathrm{N} / \mathrm{A}$ & - & - & V/A & - & - \\
\hline & 100 & 144 & 4.9 & 1 & $80 \%$ & 34.9 & 0.1 & $0.40^{\circ}$ & 34.9 & 0.1 & 0.3 & 34.9 & 0. & 2.5 & 4.9 & 0.1 & .30 \\
\hline & 500 & 144 & 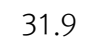 & 0.7 & 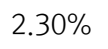 & 32 & 0 & 0.1 & 31. & 0.1 & $0.40 \%$ & 31.9 & 0.6 & $2.00 \%$ & 1.9 & 0.1 & $30^{\circ}$ \\
\hline \multirow{3}{*}{$\begin{array}{l}\text { Group II } \\
\text { (HPV39) }\end{array}$} & 0 & 144 & $/ A$ & - & - & $\mathrm{N} / \mathrm{A}$ & - & - & N/A & - & - & N/A & - & 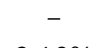 & $\mathrm{J} / \mathrm{A}$ & - & - \\
\hline & 100 & 144 & 35.9 & 0.9 & 50 & 35.9 & 0 & & 35.9 & 0 & & 35.9 & 0.8 & & 35.9 & 0.2 & $0.50 \%$ \\
\hline & 500 & 144 & 33.2 & 0.8 & $2.30 \%$ & 33.2 & 0.1 & $0.30 \%$ & 33.2 & 0.1 & $0.20 \%$ & 33.2 & 0.7 & $2.10 \%$ & 33.2 & 0.3 & $1.00 \%$ \\
\hline \multirow{3}{*}{$\begin{array}{c}\text { Group III } \\
\text { (HPV53) }\end{array}$} & 0 & 144 & $N / A$ & - & - & N/A & - & - & N/A & - & - & N/A & - & - & N/A & - & - \\
\hline & 200 & 144 & 36.6 & 0.8 & $2.20 \%$ & 36.6 & 0.2 & $0.50 \%$ & 36.6 & 0.1 & $0.40 \%$ & 36.6 & 0.7 & $1.90 \%$ & 36.6 & 0 & $0.10^{\circ}$ \\
\hline & 1000 & 144 & 33.2 & 1 & $3.10 \%$ & 33.4 & 0.1 & $0.40 \%$ & 33.3 & 0.1 & $0.30 \%$ & 33.3 & 1 & $2.90 \%$ & 33.3 & 0.1 & $0.40 \%$ \\
\hline \multirow{3}{*}{$\begin{array}{c}\text { Group III } \\
\text { (HPV56) }\end{array}$} & 0 & 144 & N/A & - & - & N/A & - & - & N/A & - & - & N/A & - & - & N/A & - & - \\
\hline & 200 & 144 & 35.3 & 1.2 & $3.50^{\circ}$ & 35.3 & 0.1 & $0.20 \%$ & 35.3 & 0.1 & $0.20 \%$ & 35.3 & 1.1 & $3.20 \%$ & 35.3 & 0.2 & $0.60^{\circ}$ \\
\hline & 1000 & 144 & 32.4 & 0.9 & $2.70 \%$ & 32.4 & 0.1 & $0.30 \%$ & 32.4 & 0 & $0.10 \%$ & 32.4 & 0.8 & $2.50 \%$ & 32.4 & 0.2 & $0.50 \%$ \\
\hline
\end{tabular}

Abbreviations: $\mathrm{N}$, test number of inter- and intra- assay; Cq, Quantification cycles; CV, coefficients of variation; SD, standard deviation; $\mathrm{N} / \mathrm{A}$, not amplified.

detected by 5000 copies of HPV per assay [19]. However, HC2 lacks internal standards to assess sample quality and cannot detect genotypes of HPVs [20-22]. HPV ViroCheck includes internal control in each well to see whether samples contain PCR inhibitors. Also, major HPV 16 and HPV 18 genotypes can be detected simultaneously. Recently, new genotyping kits using a variety of measuring instruments have been commercialized; Cobas ${ }^{\mathrm{TM}}$ HPV test (Roche Diagnostics Gmbh), the Cervista ${ }^{\mathrm{TM}}$ HPV HR test (Hologic), and the Abbott Real time high risk HPV test (Abbott Laboratories, IL, USA) performed by real-time PCR assay [23,24]. Further, comparative testing is necessary to assess the relative advantages of these systems.

Therapeutic vaccines using HPV E6/E7 have been generated to treat HPV-associated lesions and cancers, and focus on its efficacy in clinical trials. The DNA vaccine pNGVL4a-sig/ E7(detox)/HSP70 DNA vaccine was shown to enhance the HPV-16 E7 antigen-specific T cell mediated immune responses in a preclinical model [24]. Another therapeutic vaccine GX-188E, a therapeutic HPV DNA vaccine engineered to express HPV16 and HPV18 proteins E6/E7 fused to the extracellular domain of Flt3L. The clinical trial Phase I with 9 volunteers demonstrated GX-188E is safe and well tolerated by patients and shown statistically significant cellular immune response and three patients showed a weak antibody response against E7 protein [25]. The other HPV vaccine was VGX-3100. VGX-3100 is a combination of two plasmids encoding optimized HPV16 and 18 E6 and E7 antigens [26]. VGX-3100 was administered through intramuscular injection followed by electroporation to 18 female patients who had been previously treated for CIN2/3 lesions [27]. Each patient received three rounds of vaccination, which was well tolerated with no observed dose-limiting toxicities. As therapeutic vaccines using HPV E6/E7 were developed, the complementary diagnosis for follow-up of vaccine efficacy will be needed.

The HPV ViroCheck assay uses the fluorescence to detect specific HPV 16 and HPV 18 with FAM dye and 16 HR HPVs with HEX dye in only three wells. The advantages of the rapid and handy screening method. For HPV genotyping or detection, an appropriate assay should be selected on the basis of the specific purpose and conditions of each laboratory. The HPV ViroCheck genotyping kit offers another valuable option for use in the future. 


\section{요 약}

인간유두종 바이러스 (HPV)는 자궁경부암의 주요 원인이며, 자궁경부암의 주요 원인 바이러스는 16종의 고위험군 유전형 HPV 16, HPV 18, HPV31, HPV 33, HPV 35, HPV 39, HPV 45, HPV 51, HPV 52, HPV 53, HPV 56, HPV 58, HPV 59, HPV 66, HPV 68, HPV 69 이다. 특히, HPV 16형과 HPV 18형이 $\mathrm{HPV}$ 양성 암환자의 $70 \%$ 에서 발견된다. 따라서, 바이러스의 존 재 유무를 확인하는 것은 환자의 스크리닝에 도움을 주며, 최근 에 세포학적 검사와 함께 보조적인 검사법으로 사용되고 있다. 본 연구는 16종의 고위험군 바이러스와 HPV 16, HPV 18 유전 형을 검출 할 수 있는 HPV ViroCheck의 발암 유전자의 분석 성 능을 확립하기 위한 목적으로 수행되었다. 먼저, 16 종의 고위험 군 $\mathrm{HPV}$ 의 발암유전자 $\mathrm{E} 6 / \mathrm{E} 7$ 유전형의 검출한계를 확인하기 위 하여, 분석적 민감도를 수행하였다. 그리고, 관련된 미생물 및 바이러스에서의 교차반응 및 정확도를 비교하여 평가하였다. 고위험군 $\mathrm{HPV}$ 유전자형의 민감도는 Clone $\mathrm{DNA}$ 를 이용 하였 을 때, 최대 1 카피에서 100 카피까지 검출이 가능하였고, $\mathrm{SiHa}$ 세포와 Hela 세포의 경우 최소 10 세포까지 검출이 가능하였다. 자궁경부 관련 미생물 및 바이러스에서 $\mathrm{HPV}$ 유전형에 대한 교 차 반응은 나타내지 않았다. 또한, 측정법 내 변동계수 및 측정 법 간 변동계수 실험 결과 변동계수가 $5 \%$ 이하로 정확도가 높았 다. 위의 분석 성능자료는 HPV ViroCheck의 유전자형 검사의 식품의약품 안전처의 체외진단용 의료기기 허가를 위한 자료로 사용 될 것이며, 향후, HPV 16종의 발암유전자 검출과 HPV 16, $\mathrm{HPV} 18$ 유전형 검출 연구에 도움이 될 것이다.

Acknowledgements: This research was supported by Hyejeon College.

Funding: None

Conflict of interest: None

\section{REFERENCES}

1. Forman D, de Martel C, Lacey CJ, Soerjomataram I, LortetTieulent J, Bruni L, et al. Global burden of human papillomavirus and related diseases. Vaccine. 2012;30(Suppl 5):F1223.

2. Munoz N, Bosch FX, de Sanjosé S, Herrero R, Castellsagué X, Shah KV, et al. Epidemiologic classification of human papillomavirus types associated with cervical cancer. N Engl J Med. 2003;348(6):518-527.

3. Kjaer SK, Munk C, Junge J, Iftner T. Carcinogenic HPV prevalence and age-specific type distribution in 40,382 women with normal cervical cytology, ASCUS/LSIL, HSIL, or cervical cancer: what is the potential for prevention? Cancer Causes Control. 2014;25(2):179-189.

4. Castle PE, Jeronimo J, Temin S, Shastri SS, et al. Screening to prevent invasive cervical cancer: ASCO resource-stratified clinical practice guideline. J Clin Oncol. 2017;35(11):12501252.

5. Castle PE, Katki HA. Benefits and risks of HPV testing in cervical cancer screening. Lancet Oncol. 2010;11(3):214-215.

6. Herbert A. Primary HPV testing: a proposal for co-testing in initial rounds of screening to optimise sensitivity of cervical cancer screening. Cytopathology. 2017;28(1):9-15.

7. Min KJ, Lee YJ, Suh M, Yoo CW, Lim MC, Choi J, et al. The Korean guideline for cervical cancer screening. J Gynecol Oncol. 2015;26(3):232-239.

8. Lee JK, Hong JH, Kang S, Kim DY, Kim BG, Kim SH, et al. Practice guidelines for the early detection of cervical cancer in Korea: Korean Society of Gynecologic Oncology and the Korean Society for Cytopathology 2012 edition. J Gynecol Oncol. 2013;24(2):186-203.

9. Ratnam S, Coutlee F, Fontaine D, Bentley J, Escott N, Ghatage P, et al. Clinical performance of the PreTect HPV-Proofer E6/E7 mRNA assay in comparison with that of the Hybrid Capture 2 test for identification of women at risk of cervical cancer. J Clin Microbiol. 2010;48(8):2779-2785.

10. Park SM, Lee SK, Kim YS. Inhibition of cervical cancer cell growth by gene silencing of HPV16 E6 Induced by short-interfering RNA. Korean J Clin Lab Sci. 2011;43(3):89-97.

11. Thomas M, Pim D, Banks L. The role of the E6-p53 interaction in the molecular pathogenesis of HPV. Oncogene. 1999; 18(53):7690-7700.

12. Storey A, Thomas M, Kalita A, Harwood C, Gardiol D, Mantovani F, et al. Role of a p53 polymorphism in the development of human papillomavirus-associated cancer. Nature. 1998;393 (6682):229-234.

13. Caldeira S, Dong W, Tommasino M. Analysis of E7/Rb associations. Methods Mol Med. 2005;119:363-379.

14. Lee JB, Park CE. Investigation of detected by recent various human papillomavirus from general hospital in Seoul area. Korean J Clin Lab Sci. 2016;48(3):247-254.

15. Munkhdelger J, Kim GH, Wang HY, Lee DS, Kim SH, Choi YI, et al. Performance of HPV E6/E7 mRNA RT-qPCR for screening and diagnosis of cervical cancer with Thinprep pap test samples. Exp Mol Pathol. 2014;97(2):279-284.

16. Kim JH, Wang HY, Kim SY, Park SD, Yu KM, Kim HY, Uh Y, Lee HY. Evaluation of the Punch-it ${ }^{\mathrm{TM}} \mathrm{NA}-$ Sample kit for detecting microbial DNA in blood culture bottles using PCR-reverse blot hybridization assay. Journal of Microbiological Methods. 2016; 128:24-30.

17. Walsh PS, Metzger DA, Higuchi R. Chelex 100 as a medium for simple extraction of DNA for PCR-based typing from forensic material. Biotechniques. 1991;10(4):506-513.

18. Mincheva A, Gissmann L, zur Hausen H. Chromosomal integration sites of human papillomavirus DNA in three cervical cancer cell lines mapped by in situ hybridization. Med Microbiol Immunol. 1987;176(5): 245-256.

19. Terry G, Ho L, Londesborough P, Cuzick J, Mielzynska-Lohnas I, 
Lorincz A. Detection of high-risk HPV types by the hybrid capture 2 test. J Med Virol. 2001;65(1):155-162.

20. Du Chateau BK, Schroeder ER, Munson E. Clinical laboratory experience with cervista HPV HR as a function of cytological classification: comparison with retrospective digene $\mathrm{HC} 2$ high-risk HPV DNA test data. J Clin Microbiol. 2013;51(3): 1057-1058.

21. Zhou F, Pulinthanathu R, Elgert P, Cangiarella J, Simsir A. Sensitivity of high-risk HPV Hybrid Capture II (hrHPV HC2) test using SurePath(TM) specimens in the prediction of cervical high-grade squamous lesions. Diagn Cytopathol. 2015;43(5): 381-387.

22. Huijsmans CJ, Geurts-Giele WR, Leeijen C, Hazenberg HL, van Beek J, de Wild C, et al. HPV prevalence in the Dutch cervical cancer screening population (DuSC study): HPV testing using automated HC2, cobas and aptima workflows. BMC Cancer. 2016;16:922.

23. Kash N, Lee MA, Kollipara R, Downing C, Guidry J, Tyring SK.
Safety and efficacy data on vaccines and immunization to human papillomavirus. J Clin Med. 2015;4(4):614-633.

24. Yang A, Farmer E, Wu TC, Hung CF. Perspectives for therapeutic HPV vaccine development. J Biomed Sci. 2016;23:75.

25. Kim TJ, Jin HT, Hur SY, Yang HG, Seo YB, Hong SR, et al. Clearance of persistent HPV infection and cervical lesion by therapeutic DNA vaccine in CIN3 Patients. Nat Commun. 2014;30:5317.

26. Trimble CL, Morrow MP, Kraynyak KA, Shen X, Dallas M, Yan J, et al. Safety, efficacy, and immunogenicity of VGX-3100, a therapeutic synthetic DNA vaccine targeting human papillomavirus 16 and $18 \mathrm{E} 6$ and E7 proteins for cervical intraepithelial neoplasia 2/3: a randomised, double-blind, placebocontrolled phase 2b trial. Lancet. 2015;386(10008):2078-2088.

27. Morrow MP, Kraynyak KA, Sylvester AJ, Shen X, Amante D, Sakata L, et al. Augmentation of cellular and humoral immune responses to HPV16 and HPV18 E6 and E7 antigens by VGX-3100. Mol Ther Oncolytics. 2016;3:16025. 